Learning, Food, and Sustainability 

Jennifer Sumner

Editor

\section{Learning, Food, and Sustainability}

Sites for Resistance and Change 


\section{Editor}

Jennifer Sumner

University of Toronto

Toronto, Ontario, Canada

ISBN 978-1-137-53903-8

DOI $10.1057 / 978-1-137-53904-5$

ISBN 978-1-137-53904-5 (eBook)

Library of Congress Control Number: 2016947968

(C) The Editor(s) (if applicable) and The Author(s) 2016

This work is subject to copyright. All rights are solely and exclusively licensed by the Publisher, whether the whole or part of the material is concerned, specifically the rights of translation, reprinting, reuse of illustrations, recitation, broadcasting, reproduction on microfilms or in any other physical way, and transmission or information storage and retrieval, electronic adaptation, computer software, or by similar or dissimilar methodology now known or hereafter developed.

The use of general descriptive names, registered names, trademarks, service marks, etc. in this publication does not imply, even in the absence of a specific statement, that such names are exempt from the relevant protective laws and regulations and therefore free for general use. The publisher, the authors and the editors are safe to assume that the advice and information in this book are believed to be true and accurate at the date of publication. Neither the publisher nor the authors or the editors give a warranty, express or implied, with respect to the material contained herein or for any errors or omissions that may have been made.

Cover illustration: (C) simon Jonathan webb / Alamy Stock Photo

Printed on acid-free paper

This Palgrave Macmillan imprint is published by Springer Nature The registered company is Nature America Inc. New York 
Dedication of book to Cathleen Kneen

This book is dedicated to Cathleen Kneen, a contributor to this work. She was an educator, activist and friend whose spirit continues to guide us in our work on food system transformation. 



\section{Contents}

Part I Learning, Food, and Sustainability in the Home and Community

1 Learning and Food at the Mother's Breast

Susan Machum

2 The Tale of the Crying Rice: The Role of Unpaid Foodwork and Learning in Food Waste Prevention and Reduction in Indonesian Households

Tammara Soma

3 Learning, Food, and Sustainability in Health Care Settings

Donna Appavoo

Part II Learning, Food, and Sustainability in the School

4 Learning, Food, and Sustainability in the School Curriculum

Pamela A. Koch 
5 Developing a Learning Garden on a Mid-Western

Land Grant University

Christopher D. Murakami

6 Food Education: From Normative Models to Promoting Agency

Kristiina Janhonen, Johanna Mäkelä, and Päivi Palojoki

Part III Learning, Food, and Sustainability in Social Movements

7 Learning through Story as Political Praxis: The Role of Narratives in Community Food Work

Kim L. Niewolny and Phil D'Adamo-Damery

8 Learning, Food, and Sustainability in

Community-Campus Engagement: Teaching and Research Partnerships That Strengthen the Food Sovereignty Movement

Peter Andrée, Lauren Kepkiewicz, Charles Levkoe, Abra Brynne, and Cathleen Kneen

9 Re: Claiming Food Sovereignty, Reclaiming

Ways of Knowing: Food Justice Course Digs Deeper Deborah Barndt

Part IV Learning, Food, and Sustainability: Tools for the Future

10 Youth and Food Literacy: A Case Study of Food Education at The Stop Community Food Centre Sarah Goldstein 
11 School Food and Nutrition Policies as Tools for Learning

Mary McKenna and Sharon Brodovsky

12 Learning to Transgress: Creating Transformative Spaces in and Beyond the Classroom

Angie Carter, Claudia M. Prado-Meza, and Jessica Soulis

Afterword: Food 360: Seeing Our Way Around Learning About Food

Wayne Roberts

Glossary Of Terms

Index 



\section{List of Figures}

Fig. 4.1 The change process for nutrition and food-based education in schools

Chart 10.1 Distribution of the six most prevalent food literacy benchmarks in FLY participants as coded in research data

Fig. 11.1 CSH framework (Joint Consortium for School Health 2015) 203 



\section{LisT OF TABLES}

Table 5.1 Participant name and brief description of campus affiliation

Table 10.1 Benchmarks of food literacy as identified in academic and organizational literature 



\section{Author Biographies}

Peter Andrée is an associate professor in the Department of Political Science at Carleton University in Ottawa. His research focuses on the politics of food and the environment, and he practices, and teaches, community-based participatory research methods. He is co-editor of Globalization and Food Sovereignty: Global and Local Change in the New Politics of Food, which examines social movements the world over seeking to build more sustainable and just food systems.

Donna Appavoo has a background in human nutrition and teaches in the Chang School at Ryerson University in Toronto, as well as being an administrator and researcher with Appavoo Medicine Professional Corporation. Her interests include food systems, health systems, food security, gender, sustainability and ecohealth.

Deborab Barndt is a professor emerita in the Faculty of Environmental Studies at York University in Toronto and an artist and activist around environmental and social justice issues in the Americas. She is the author of Tangled Routes: Women, Work, and Globalization on the Tomato Trail, and has written numerous book chapters and articles on food, arts-based education, and the global food system.

Sharon Brodovsky holds a Master's in Business Administration from the University of Toronto and works as a social impact strategist. She leads a consulting practice that supports social sector organizations, foundations and private companies to design, develop and implement social impact strategies, plans and evaluative tools to monitor, demonstrate and communicate impacts.

Abra Brynne grew up on a farm in the Okanagan Valley and, as part of a family of 13 , learned the value of co-operation, good food, and hard work from an early age. Abra has worked closely with farmers and on food systems for the past twentyfive years, with a priority on place-based food systems and the regulatory regimes that impede or support them. Most recently she has been incorporating Indigenous 
food sovereignty and sustainable fisheries into her work. She is a founding member and special advisor to the Canadian Biotech Action Network, and a founding member of both Food Secure Canada and the BC Food Systems Network. She is currently the Director of Engagement and Policy at the BC Food Systems Network.

Angie Carter has a PhD in sociology and sustainable agriculture from Iowa State University and teaches at Augustana College. Her research interests include power and social change within agricultural systems, social justice, and gender. She is also a board member of her local food co-operative and the Women, Food and Agriculture Network.

Phil D'Adamo-Damery is a postdoctoral research associate in the Department of Agricultural, Leadership and Community Education at Virginia Tech. His work is focused on exploring the politics of community education and strengthening possibilities for social justice and food systems change.

Sarab Goldstein is a trained chef, volunteer youth food educator and recent graduate of York University's Master of Environmental Studies program. Her research centered on reclaiming the food system through sustainability and education, with a focus on how to build a sustainable food system, alternative food movements in sustainability and culture, and strategies for food education and food literacy education. During the course of her master's program, she worked with Evergreen Brickworks and their Green City Adventure Camp, where she developed and implemented food programming for elementary-aged children.

Kristiina Janhonen is a doctoral student working in the Department of Teacher Education at the University of Helsinki. She received her Master's degree in Education in 2009 from the University of Helsinki. Her PhD dissertation examines adolescents' food education through quantitative and qualitative methods.

Lauren Kepkiewicz is a $\mathrm{PhD}$ candidate in the Department of Geography and Planning at the University of Toronto. Through her research, she aims to understand the ways that food connects people to land in the context of the Canadian settler colonial state. Lauren is also employed as a research assistant for the Community First: Impacts of Community Engagement (CFICE): Community Food Security Hub and has worked for organizations such as Irvine Creek Organic Farm, Katimavik, and Africa Youth for Peace and Development.

Catbleen Kneen was a veteran of the peace, social justice, women's, and food security movements. Since 1980, she and her husband Brewster Kneen copublished The Ram's Horn, a monthly newsletter of analysis of the food system. She chaired Just Food Ottawa for eight years and was the Chair of the newly formed Ottawa Food Policy Council, while continuing to represent Food Secure Canada in several capacities, including the Technical Committee for the Canada Organic Standard and the North American committee of the Civil Society Mechanism for the FAO Food Security commission. 
Pamela Koch is the executive director of the Laura M. Tisch Center for Food, Education and Policy at Columbia University. She has a doctorate in Nutrition Education and is also a registered dietician. She conducts research and creates resources that are at the intersection of food systems, nutrition education, and public policy.

Charles Levkoe is the Canada Research Chair in Sustainable Food Systems and an Assistant Professor at Lakehead University. He is the principal investigator of a research project focusing on the role of non-wage labour on small-scale ecologically oriented farms and also the academic co-lead on CFICE: Community Food Security Hub, a major cross-Canada initiative exploring community campus engagement. His broader research focuses on the role of grassroots organizations in relation to sustainable food systems, their connection to place, and their ability to mobilize across sectors, scales, and places.

Susan Machum has a PhD from the University of Edinburgh and holds a Canada Research Chair in Rural Social Justice at St. Thomas University in Fredericton, New Brunswick. Her research explores the relationship between rural and urban communities, food systems and women's contributions to agriculture. She uses a participatory action research model to engage rural communities and activists in theoretically informed social change agendas.

Jobanna Mäkelü is Professor of Food Culture in the Department of Teacher Education at the University of Helsinki. She has previously worked as the head of food research at the National Consumer Research Centre. Her field of expertise lies in sociology and food and consumer studies.

Mary McKenna is a registered dietician and a professor in the Faculty of Kinesiology at the University of New Brunswick. She has written extensively in the areas of school nutrition, and is a member of Food Secure Canada, Farm to Cafeteria Canada, the Canadian Child and Youth Nutrition Program Network, Dietitians of Canada and the New Brunswick Minister's Roundtable for Agriculture.

Christopher Murakami is a PhD candidate in the Department of Learning, Teaching and Curriculum at the University of Missouri, where he works as a graduate research assistant and the manager of the MU Children's Learning Garden. He has a teaching credential in secondary science education and has written both popular and scholarly articles on science education.

Kim L. Niewolny is an assistant professor in the Department of Agricultural, Leadership and Community Education at Virginia Tech. Her areas of scholarship interest include participatory forms of adult, extension and community-based education, community and rural development, and action research and communitybased participatory research. 
Päivi Palojoki is Professor of Home Economics Pedagogy in the Department of Teacher Education at the University of Helsinki. She has a background in education and food science, and her expertise lies in research on the relationship of food choice and nutrition knowledge and the development of home economics pedagogy on different levels of schooling. She is the leader of the Food, Culture and Learning research group at the University of Helsinki.

Claudia M. Prado-Meza has been a professor at the Faculty of Economics, Universidad de Colima, since she graduated with a PhD in Sustainable Agriculture and a certificate in Social Justice in Higher Education from Iowa State University in 2013. Her interests are local food systems, transnationalism, social justice and gender. She is also the president of the non-governmental organization PROCEDER AC that looks for ways to creatively teach about human rights to high school students from Colima, Mexico.

Wayne Roberts is a leading policy analyst and practitioner in the areas of food, public health and urban planning. He managed the world-renowned Toronto Food Policy Council for many years, and has served on the boards of the Community Food Security Coalition, Food Secure Canada, FoodShare and the Unitarian Service Committee of Canada. He is the author of The No-Nonsense Guide to World Food and a recipient of the Queen's Jubilee Medal in recognition of his contribution to community service.

Tammara Soma is a PhD candidate in the Department of Geography and Planning at the University of Toronto. Her research interests include food security, food systems planning, sustainable agriculture and food waste. Her thesis focuses on household food consumption and waste in urban Indonesia.

Jessica Soulis is a food systems and sustainable agriculture consultant who graduated from Iowa State University with an MS in sustainable agriculture and sociology and a certificate in Social Justice in Higher Education. Her research interests include social justice, food access and health, and food sovereignty. She serves on the board of the Iowa Food Systems Council and was a founder and editorial board member of the Journal of Critical Thought and Praxis.

Jennifer Sumner teaches in the Adult Education and Community Development Program at the Ontario Institute for Studies in Education at the University of Toronto. Her research interests include food and food systems, co-operatives, globalization, sustainability, rural communities and critical pedagogy. She is the author of Sustainability and the Civil Commons: Rural Communities in the Age of Globalization and co-editor of Critical Perspectives in Food Studies. 


\title{
INTRODUCTION
}

\author{
Jennifer Sumner
}

Learning and food are central to human existence. Learning helps us to survive and evolve as a species, while food provides us with the glue that holds our survival and evolution together. In tandem, they form a dynamic combination that has fueled change for millennia.

In spite of their centrality to human existence, learning and food have seldom been addressed at the same time. Those who study learning have not often turned their gaze toward food, while those who study food have generally overlooked the learning associated with it. And yet, food is not only an object of learning but also a vehicle for learning (Flowers and Swan 2012). In essence, food is inherently pedagogical, and eating is a pedagogical act (Sumner 2008a) as is producing, processing, distributing, purchasing, and disposing of food. What we learn, and do not learn, by engaging in these human endeavors has deep and enduring implications for the sustainability of our food systems and our world.

This book explores the complex intersection of learning and food in the home and community, in the classroom, in social movements, and into the future, all within the context of contributing to more sustainable food systems.

\section{LEARNING}

Learning is the process of gaining new knowledge, of synthesizing acquired knowledge, and of rejecting knowledge that is no longer fit for purpose. It is much broader than education and refers to any elements that combine to produce a change in mental constructs or behaviors (Spencer 
and Lange 2014). As such, learning is also a lifelong process, from babies learning to use eating utensils and adolescents learning to cook for themselves, to adults learning to feed a family, and seniors learning to link nutrition and healthy aging.

While learning is lifelong, not all learning is positive. Spencer and Lange (2014) raise this issue when they discuss people learning how to use cocaine or how to con pensioners out of their savings. In the same vein, people can also learn to see frozen microwaveable dinners as the food of the future, to consider fast food as comfort food, or to equate the consumption of junk food with freedom. All of these examples highlight the fact that "learning defies easy definition and simple theorizing" (Merriam and Caffarella 1999, 248).

Learning is generally divided into three main categories: formal, nonformal, and informal learning (Hrimech 2005), all of which have close associations with food. Formal learning takes place in classrooms at all levels-from nursery school to graduate school. While often didactic, it can also be collaborative, with teachers and students learning together and from each other. Primary students learning about basic nutrition, secondary students learning about food and water issues, culinary students learning how to incorporate local food into their menus, and university students studying the political economy of food are all examples of formal learning.

Non-formal learning occurs in planned situations outside the classroom such as retreats, seminars, and workshops. This kind of learning is actively chosen by participants who are seeking expertise in a desired area, such as composting, pickling, or permaculture. One form of collective nonformal learning that evolved from the Danish folk schools is kitchen-table meetings. For example, the Ecological Farmers of Ontario hold kitchentable meetings at designated farms during the winter months as a forum to teach each other about specific aspects of organic farming (Sumner 2008b).

Informal learning takes place through everyday encounters and selfteaching. Though the most common form of learning, it is also the least recognized. In spite of this lack of recognition, people learn all the time as they go about their daily lives-working, shopping, playing, traveling, watching television, surfing the internet, meeting friends, and dining with family. Reading the ingredients on a food label, talking to your neighbor about allotment gardens or setting aside a day to teach yourself how to make bread are all examples of informal learning. 
Crosscutting these traditional divisions are particular types of learning, such as experiential learning, embodied learning, and transformative learning. Experiential learning links life experiences and learning, keeping in mind that "experience can be very problematic" and people may have to unlearn experiences of racism or abuse (Spencer and Lange 2014, 9). Boud (2005) maintains that experiential learning is commonly used in two different senses: it describes the prior learning that is brought to a new experience, and it refers to learning processes in which the learner's experience provides the prime source and stimulus for learning. School gardens, cooking classes, and worm composting all offer opportunities for experiential learning.

Embodied learning reminds us that we not only learn with the mind but also the body. "Embodied learning is a way of recognizing that we know with our bodies as well as our minds, to reclaim our wholeness as learners" (Clark 2005, 210). The story of French author Marcel Proust biting into a madeleine and feeling an explosion of memories is a prime example of embodied learning.

Transformative learning occurs in the face of a disorienting dilemma and results in a fundamental shift in worldviews. Unlike other forms of learning, it involves a "deep, structural shift in basic premises of thought, feelings and actions" (TLC 2015). Watching a film like Food Inc., eating food you have grown yourself or going to a slaughterhouse can result in transformative learning.

In essence, learning occurs every day, in many ways, and one of the greatest catalysts for all sorts of learning is food.

\section{FOOD}

Food has always been associated with learning, from our earliest ancestors learning how to grow food instead of hunting and gathering it, to modern shoppers learning how to navigate competing messages in the supermarket: Local or global? Conventional or organic? Fair trade or free trade? The answers to these questions, and many more, highlight the overwhelming complexity of food. In the words of Welsh and MacRae (1998, 242):

Food is a nexus for industry, rural/urban relations, global trade relations, domestic and social life, biological health, social belonging, celebration of community, paid and unpaid work, expressions of care, abuse of power, hunger strikes, fasts and prayer. Food is part of daily life at least as much as we are consumers and possibly more as we labour for either love or money. 
Clearly, food is much more than simply fuel for the body-it carries deep social, cultural, economic, and environmental implications that people experience every day. And because food has long been associated with wealth and power (Friedmann 1993), it also intersects with questions of gender, race, class, ethnicity, and imperialism. For all these reasons, food engenders learning, whether we learn to adapt to eating nutritionally compromised industrial food (see Winson 2013) or whether we learn to demand food that is healthy, green, fair, accessible, and affordable.

The growing interest in food has created a whole new vocabulary to learn, such as food miles, food deserts, food systems, food justice, and food pedagogies. Food miles represent the distance that food has traveled from field to fork. The concept emphasizes the relationship between the calories available in the food and the energy expended to transport it to the place where it will be consumed, as well as the oil and carbon emissions associated with this transportation. In a global economy, food travels enormous distances. For example, Xuereb (2005) estimates that food items sold in southern Ontario, Canada, have traveled, on average, about 4500 kilometers from the place they were grown or raised. Learning to eat "closer to home" helps to reduce food miles and supports the local economy.

The evocative concept of food deserts was developed by food policy researchers in the UK to characterize human settlements lacking access to a variety of healthy and affordable foodstuffs (Winson 2004). Highlighting the fact that access to food is not only limited by income but also by such factors as geography and distribution, food deserts are areas with insufficient numbers of stores and other food-related facilities that provide access to fresh and healthy foods (Koç et al. 2012). They are often found in low-income and/or minority urban communities but can also be found in rural communities, schools, universities, bus stations, airports, and along major highways. Communities in food deserts can learn to create food oases by opening a food co-op, participating in a food-box program or lobbying policy makers to address food desert issues.

Food systems are interdependent webs of activities that include the production, processing, distribution, retailing, consumption, and disposal of food (Sumner 2012). Like all systems, food systems are interconnected in such a way that they produce their own pattern of behavior over time (Meadows 2008). This behavior affects both humans and the environment in positive or negative ways, depending on how the system is organized and who benefits from this organization. For example, the current global food system is organized to benefit large multinational food corporations, 
not the one billion people who go hungry every day. A sustainable food system would be organized to benefit the majority of people in the world by ensuring everyone was fed within the ecological limits of the planet (Sumner 2012).

Food justice is associated with a growing social movement of food activists who emphasize production that is not only environmentally sustainable but also socially just, taking into account workers in all sectors of the food system (Koç et al. 2012). These activists bring an anti-oppression analysis to the question of food system transformation, linking anti-racism, feminism, and Indigenous rights movements to the food movement. Learning to participate in boycotts and buycotts - that is, deliberately choosing not to purchase or actively choosing to purchase a product-is one of many ways to work toward food justice.

The concept of food pedagogies brings the realms of food and learning together in a novel combination that evokes engagement and transformation. Food pedagogies have been described as:

Congeries of education, teaching and learning about how to grow, shop for, prepare, cook, display, taste, eat and dispose of food by a range of agencies, actors and media; and aimed at a spectrum of "learners" including middle class women, migrants, children, parents, shoppers, and racially minoritised and working class mothers. (Flowers and Swan 2012, 425)

For these authors, food pedagogies encompass either intended or emergent change-whether in behavior, habit, emotion, cognition, and/or knowledge - at a range of levels, from the individual, through the family to the group and collective level. Following the tenets of critical pedagogy (e.g., Finger 2005), critical food pedagogies entail a range of approaches that are not just concerned with any type of change but with change that addresses power and injustice (Sumner 2015). Brazil's new dietary guidelines are an inspiring example of critical food pedagogy because they encourage people to avoid fast-food restaurants and processed food and warn about the propaganda inherent in food advertising.

All in all, as Roberts (2013) contends, food is a hot topic-for two reasons. First, many people have come to realize that food cannot be taken for granted any longer. And second, many people have also become excited about food projects that "help them find their voice and satisfy their desires for a meaningful, engaged, empowered and authentic life" (11). Such a life will only be fully realized within a framework of sustainability. 


\section{Sustainability}

Sustainability is a word that is commonly used but seldom understood. It came to prominence with the publication in 1987 of the Brundtland Report-Our Common Future-which promoted the concept of sustainable development. A vague and contested term sustainability has been associated with a bewildering range of ideas, from the Dow Jones Sustainability Index to Deep Ecology (Sumner 2007). But its appropriation by self-serving interests should not disqualify it from use. Originally associated with environmental problems, it has expanded to cover social and economic issues as well, making it ripe with learning opportunities and ideal for analyzing food.

In its most undeveloped form, sustainability entails the ability to meet present needs without compromising the ability of future generations to meet their own needs (Koç et al. 2012). While this adaptation from the Brundtland Report has gained familiarity, it does not define the term "needs" and is premised on ever-expanding economic growth, which global warming is currently teaching us to question. A recent definition involves a more focused approach, linking it with the concept of the civil commons-co-operative human constructions that protect and/or enable universal access to life goods such as water, shelter, education, health-care, and, of course, food (Sumner 2007). Linking sustainability to the provision of life goods addresses the problem of needs and does not depend on economic growth-it could thrive in a steady-state economy. In short, building the civil commons by providing more life goods makes us more sustainable; enclosing the civil commons by providing fewer life goods makes us less sustainable. Nowhere is this clearer than in the realm of food. And given that sustainability doesn't come naturally-but has to be learned (Sumner 2007) —linking learning, food, and sustainability brings together three vital aspects of our future as a species.

\section{Putting It All Together: Learning, Food, and Sustainability}

Interest in food has burgeoned over the last 20 years for a number of reasons, beginning with the consolidation of the global corporate food system. This consolidation has resulted in growing corporate control over what we eat, the pervasive commodification of food, and the spread of the 
so-called Western diet-highly processed foods laden with salt, sugar, and fat. Under this system,

Food is no longer viewed first and foremost as a sustainer of life. Rather, to those who seek to command our food supply, it has become instead a major source of corporate cash flow, economic leverage, a form of currency, a tool of international politics, an instrument of power - a weapon! (Krebs 1992 in Millstone and Lang 2003, 11)

In reaction to the increasing corporate control of this vital life good, a number of social movements have coalesced around the subject of food. For example, the local food movement questions the distance that food now travels and champions food close to home. The food justice movement condemns the injustices associated with the global corporate food system. And the food sovereignty movement demands that peoples and nations should be able to choose their own foodways, instead of being forced (through supra-national mechanisms such as trade agreements) into the global corporate food system.

Hot on the heels of these food movements have come popular books and articles dedicated to food, led by authors like Michael Pollan, Marion Nestle, Eric Schlosser, and Raj Patel. These publications have been followed by scholarly interest in this rising phenomenon. A number of academic disciplines have already recognized the importance of foodincluding sociology, geography, planning, and history - spawning a host of textbooks, conferences, special journal issues, and courses on the subject.

In short, food is one of the fastest growing areas of study in many fields, but education is just beginning to grapple with what Belasco (2007, 5) described as this "edible dynamic" (e.g., Sumner 2008a, 2013a, b; Flowers and Swan 2012; Swan and Flowers 2015; Walter 2013). Such engagement is crucial, given the mounting evidence that our global corporate food system has become massively unsustainable. Goodman et al. $(2014,4)$ describe the glaring and multifaceted contradictions of this system and "the exploitative trading relations embedded in the global supply chains that support its growth and (expanded) reproduction." They go on to describe the food insecurity and malnutrition of over one billion people, the interrelated ecological and livelihood crises, the growing global resource constraints on our intensive, fossil-fuel-dependent agriculture, and the disease crises associated with Western lifestyles and diets focused on animal fats and highly processed industrial food, more 
accurately referred to as "edible food-like substances" by Michael Pollan $(2008,1)$. Faced with a suite of environmental, social, cultural, and economic problems associated with the global corporate food system, it is time to ask: What is the role of education? Does it merely promote adaptation to this unsustainable system or can it encourage the kind of learning experiences that will contribute to much-needed change?

This edited volume will be the first to address these questions by exploring the intersection of learning and food at the interface with sustainability. Taking a broad pedagogical approach to the question of food, it will focus on learning, resistance, and change in a number of key sites-homes, communities, schools, and social movements-while also looking to the future. The ultimate aim of the book involves learning our way out of our current unsustainable food system and learning our way in to more sustainable alternatives.

All the chapters in this book link learning, food, and sustainability in creative and instructive ways. Within the home and community, Chapter 1 focuses on one of the most intimate links between food and learningbreastfeeding. Susan Machum explains how breastfeeding involves a steep learning curve for mothers and newborns, including the move from abstract knowledge to praxis. After briefly reviewing breastfeeding practices over the last century, she explores the options available to families, particularly within the larger context of the tensions between initiatives that support breastfeeding and the concurrent backlash against it. She concludes that providing mothers with emotional and financial security are some of the parameters of a sustainable food system.

Learning to prevent food waste at home is the topic of Chapter 2. With the global issue of food waste as a backdrop, Tammara Soma looks at women's unpaid foodwork in Indonesia and how children are taught to eat all their food through folktales and the Islamic concept of "mubazir," meaning acts of wasting and being excessive, which are considered sinful. These pedagogical tools help to reduce or prevent food waste and contribute to a more sustainable food system.

Chapter 3 visits community health-care settings with Donna Appavoo, where the educational tools used by professionals ignore the interdependence of food systems and health systems, and focus narrowly on biological markers and daily energy requirements. An emerging narrative is challenging this focus on the nutrient constituency of foods by prioritizing community food security-described by Hamm and Bellows $(2003,37)$ as a "a situation in which all community residents obtain a safe, culturally 
acceptable, nutritionally adequate diet through a sustainable food system that maximizes community self-reliance and social justice." By broadening the focus to include "local sustainable food" and "sense of community," this alternative narrative uncovers and supports the many facets of the interconnections between food systems and health systems, and facilitates addressing complex inter-systemic issues such as diabetes.

Schools provide another site where learning, food, and sustainability connect and inspire. In Chapter 4, Pamela Koch looks at the school curriculum, arguing that food-based education needs to both consider larger food system issues and fit into the practices of the current education system. Ultimately, food-based education would encourage students to know which foods are healthy, ecologically sustainable, and socially just. In this way, students would be equipped with the critical knowledge and analytical skills to make challenging decisions about food in the future.

Learning gardens are the topic of Chapter 5 , in particular the process of developing a children's learning garden at a Land Grant University in the USA. While seemingly a reasonable and straightforward idea, implementing it became a learning project in itself as Christopher Murakami and fellow university students in the preschool and teacher training program had to negotiate the politics, policies, and culture of a large institution. The result was a compromise that straitened their original goals but nevertheless created a bridgehead that helps children develop a healthy relationship with the food, nature, and community.

Chapter 6 continues the focus on schools with an investigation into the development of food education in the Finnish comprehensive school setting. Finland has a long history of engagement with healthy food. For example, the provision of tax-paid, nutritious, hot school meals has been part of health promotion in Finnish schools for over 60 years. Kristiina Janhonen, Johanna Mäkelä, and Päivi Palojoki make a case for taking students' agency and participation as premises for educating about food and eating. As well as promoting personal well-being and health, food education is seen as a medium for understanding the complexities of the world and for supporting sustainable lifestyles embedded in everyday practices.

The next section hones in on social movements as sites of resistance and change. Chapter 7 examines alternative food movements and the role of narratives in community food work. Beginning with the idea of education as cultural work, Kim L. Niewolny and Phil D'Adamo-Damery illustrate the educative role that narratives can play in engendering 
political praxis and new possibilities. In particular, they look at the Appalachian Foodshed Project to show how narratives and storytelling can open up ways to humanize the "wicked problem" of food insecurity while creating new possibilities in the everyday work of resistance and learning.

Chapter 8 proposes campus-community engagement as a means to strengthen the food sovereignty movement. La Via Campesina, a world-wide peasant organization that is the largest social movement in the world (Friedmann 2012), coined the term food sovereignty, which entails the right of peoples and governments to determine their own agriculture systems, food markets, environments, and modes of production. Using community-service learning, Peter Andrée, Lauren Kepkiewicz, Charles Levkoe, Abra Brynne, and Cathleen Kneen consider how movements for food sovereignty and community-campus engagement can work together to provide academics with important training for critically engaging with food systems, to encourage knowledge sharing between social movement actors and academics, and to support social movement organizations working toward more just and sustainable food systems.

Chapter 9 rounds out the social movement section by considering the food justice movement through a certificate course offered by the Coady Institute at St. Francis Xavier University in Antigonish, Nova Scotia. Deborah Barndt reflects critically on the challenges associated with two shifts: one from dominant notions of food security to a consciousness based on food justice and food sovereignty and the other from dominant educational models to popular education methods that valorize Indigenous knowledges and holistic ways of knowing.

The final section of the book looks toward the future. Chapter 10 investigates food literacy, in particular among young people. Although food education programs have grown in popularity in recent years, their outcomes are unclear. Are they contributing to a food-literate population and, if so, what kind of food literacy is being achieved and what are the prospects for food system change? Sarah Goldstein studied food education at The Stop Community Food Centre in Toronto and discovered that by focusing on individual behavior modification, the program primarily facilitates the dominant food literacy paradigm based on neoliberal consciousness. For this reason, it does not necessarily lead to wider food system change, thus raising the question of what is the best form of food education 
for the future if we want a more critical and engaged food literacy and a more sustainable food system.

School food and nutrition policies as tools for learning and change are the subject of Chapter 11. Mary McKenna and Sharon Bodovsky propose that teaching about such policies in schools moves them from the hidden curriculum-part of the unspoken academic, social, and cultural messages communicated to students-and makes them explicit. This move changes students from being passive recipients of policy to active participants in all aspects of the process. As a result, students gain greater understanding of school food environments, become engaged in a personally relevant topic, and enhance their development as future citizens.

Chapter 12 of the book involves learning to transgress-that is, learning to ask how we can learn our way out of our current unsustainable food system and learn our way into more sustainable alternatives. Angie Carter, Claudia M. Prado-Meza, and Jessica Soulis were students in a sustainable agriculture program at a public, land-grant university in the USA. They used their experiences as both students and agents of social change to better understand the unlearning and relearning process and the creation of community as a transformative space. They also inquired how their experiences can inspire others as they collectively unlearned their way into more sustainable food systems.

The Afterword by Wayne Roberts sums up the importance of learning and food. After highlighting the invisibility of food in educational systems and society at large, he vividly describes a number of potential and actual transformative exceptions where food is not only visible but also front and center. Using illustrations from his own broad food experience, he outlines how schools and communities provide permeable sites where people can learn resistance and change and realize that a more sustainable food system is possible.

Together, these chapters offer an opening to a world made more sustainable by the conscious recognition of the connections between learning and food. In their study of alternative food networks, Goodman et al. (2014) observed that food is a realm of knowledge. "Growing and eating are both practices imbued with ways of knowing the world, and with knowing the ways to construct the kind of world we want to inhabit" (44). The kind of world most people want to inhabit is more sustainable than our current one. The chapters in this book show how learning about food and broader food issues can make us more sustainable and inspire us to begin constructing that world. 


\section{REFERENCES}

Belasco, W. (2007). Appetite for change: How the counterculture took on the food industry (2nd ed.). Ithaca/London: Cornell University Press.

Boud, D. (2005). Experiential learning. In L. M. English (Ed.), International encyclopedia of adult education (pp. 243-245). New York: Palgrave Macmillan.

Clark, M. C. (2005). Embodied learning. In L. M. English (Ed.), International encyclopedia of adult education (pp. 210-212). New York: Palgrave Macmillan.

Finger, M. (2005). Critical theory. In L. M. English (Ed.), International encyclopedia of adult education (pp. 165-168). New York: Palgrave Macmillan.

Flowers, R. \& Swan, E. (Eds.). (2012). Special issue on food pedagogies. Australian Journal of Adult Learning, 52(3), 532-572.

Friedmann, H. (1993). After Midas's feast: Alternative food regimes for the future. In P. Allen (Ed.), Food for the future: Conditions and contradictions of sustainability (pp. 213-233). New York: John Wiley and Sons, Inc.

Friedmann, H. (2012). Changing food systems from top to bottom: Political economy and social movements perspectives. In M. Koç, J. Sumner, \& A. Winson (Eds.), Critical perspectives in food studies (pp. 16-32). Toronto: Oxford University Press.

Goodman, D., Dupuis, E. M., \& Goodman, M. K. (2014). Alternative food networks: Knowledge, practice and politics. New York: Routledge.

Hamm, M. W., \& Bellows, A. C. (2003). Community food security and nutrition educators. Journal of Nutrition Education and Behavior, 35(1), 37-43.

Hrimech, M. (2005). Informal learning. In L. M. English (Ed.), International encyclopedia of adult education (pp. 310-312). New York: Palgrave Macmillan.

Koç, M., Sumner, J., \& Winson, A. (Eds.). (2012). Critical perspectives in food studies. Toronto: Oxford University Press.

Meadows, D. H. (2008). Thinking in systems: A primer. White River Junction: Chelsea Green Publishing.

Merriam, S. B., \& Caffarella, R. S. (1999). Learning in adulthood (2nd ed.). San Francisco: Jossey-Bass.

Millstone, E., \& Lang, T. (2003). The Penguin atlas of food. New York: Penguin Books.

Pollan, M. (2008). In defense of food: A eater's manifesto. New York: The Penguin Press.

Roberts, W. (2013). The no-nonsense guide to world food. Oxford: New Internationalist Publications Inc.

Spencer, B., \& Lange, E. (2014). The purposes of adult education: An introduction. Toronto: Thompson Educational Publishing.

Sumner, J. (2007). Sustainability and the civil commons: Rural communities in the age of globalization. Toronto: University of Toronto Press. 
Sumner, J. (2008a). Eating as a pedagogical act: Food as a catalyst for adult education for sustainability. Kursiv: Journal fuer politische Bildung, 4, 32-37.

Sumner, J. (2008b). Protecting and promoting Indigenous knowledge: Environmental adult education and organic agriculture. Studies in the Education of Adults, 40(2), 207-223.

Sumner, J. (2012). Conceptualizing sustainable food systems. In M. Koç, J. Sumner, \& A. Winson (Eds.), Critical perspectives in food studies (pp. 326-336). Toronto: Oxford University Press.

Sumner, J. (2013a). Food literacy and adult education: Learning to read the world by eating. Canadian Journal for the Study of Adult Education, 25(2), 79-92.

Sumner, J. (2013b). Eating as if it really mattered: Teaching The Pedagogy of Food in the age of globalization. Brock Education Journal, 22(2), 41-55.

Sumner, J. (2015). Waging the struggle for healthy eating: Food environments, dietary regimes and Brazil's dietary guidelines. Local Environment. DOI: $10.1080 / 13549839.2015 .1087480$

Swan, E., \& Flowers, R. (Eds.). (2015). Food pedagogies. London: Ashgate.

TLC. (2015). About the transformative learning centre, transformative learning centre. Retrieved September 20, 2015, from http://tlc.oise.utoronto.ca/ About.html

Walter, P. (2013). Theorising community gardens as pedagogical sites in the food movement. Environmental Education Research, 19(4), 521-539.

Welsh, J., \& MacRae, R. (1998). Food citizenship and community food security: Lessons from Toronto, Canada. Canadian Journal of Development Studies, XIX, 237-255.

Winson, A. (2004). Bringing political economy into the debate on the obesity epidemic. Agriculture and Human Values, 21, 299-312.

Winson, A. (2013). The industrial diet: The degradation of food and the struggle for healthy eating. Vancouver: UBC Press.

Xuereb, M. (2005). Food miles: Environmental implications of food imports to Waterloo region. Region of Waterloo Public Health. Retrieved November 28, 2015, from http://chd.region.waterloo.on.ca/en/researchResourcesPublications/resources/FoodMiles_Report.pdf 